\title{
Antennal Sensillum Distribution of Some Butterflies (Rhopalocera: Lepidoptera) Using Scanning Electron Microscopy (SEM)
}

\author{
Surabhi Talwar ${ }^{*}$ iD \\ Department of Zoology and Environmental Sciences, Punjabi University, Patiala-147002, India \\ *Corresponding author: surabhitalwar91@gmail.com
}

Geliş Tarihi: 07.02.2021

Kabul Tarihi: 08.06.2021

\begin{abstract}
Antennae of five male butterflies namely Danaus chrysippus (Linnaeus) (Danaidae), Pontia daplidice moorie (Rober) (Pieridae), Junonia lemonias (Linnaeus) (Nymphalidae), Chilades pandava Horsfield (Lycaenidae) and Papilio demoleus demoleus Linnaeus (Papilionidae) have been studied under scanning electron microscope for observing the type and number of sensilla dispersed on their component segments i.e. scape, pedicel and flagellum. The antenna of $P$. demoleus demoleus shows the presence of seven sensilla i.e., Böhm, Trichodea, Squamiformia, Chaetica, Basiconica, auricillica and Clavate. On the other hand, P. daplidice moorie and J. lemonias show the presence of only five first mentioned sensilla. However, C. pandava possesses four sensilla whereas D.chrysippus carries six sensilla, all from the seven sensilla category indicated above. Structure and location of all the sensilla on the antennal surface has been studied and illustrated in detail.
\end{abstract}

Keywords: Böhm, Trichodea, Squamiformia, Chaetica, Basiconica, Auricillica, Clavate

\section{Taramalı Elektron Mikroskobu (SEM) Tekniği Kullanılarak Bazı Kelebekler (Lepidoptera: Rhopalocera)'in Antennal Sensillum Dağılımının İncelenmesi $\ddot{\mathbf{O z}}$}

Beş erkek kelebeğin; Danaus chrysippus (Linnaeus) (Danaidae), Pontia daplidice moorie (Rober) (Pieridae), Junonia lemonias (Linnaeus) (Nymphalidae), Chilades pandava Horsfield (Lycaenidae) ve Papilio demoleus demoleus Linnaeus (Papilionidae) antenleri bileşen bölümleri (Scape, Pedicel ve Flagellum)'ne dağılmış sensilla tipini ve sayısını gözlemlemek için taramalı elektron mikroskobu altında incelenmiştir. Çalışmanın sonuçlarına göre, Papilio demoleus demoleus Linnaeus anteninde böhm, trichodea, squamiformia, chaetica, basiconica, auricillica ve clavate olmak üzere yedi farklı sensilla bulunmuştur. Öte yandan, Pontia daplidice moorie (Rober) ve Junonia lemonias (Linnaeus) antenleri üzerinde yukarıda bahsedilen ilk beş sensilla (böhm, trichodea, squamiformia, chaetica ve basiconica)'nın bulunduğu tespit edilmiştir. Ancak yukarıda belirtilen tüm yedi sensilla kategorisinden Chilades pandava (Horsfield)'nın dört sensilla oysa Danaus chrysippus (Linnaeus)'un altı sensilla taşıdıkları ortaya konulmuştur. Anten üzerindeki tüm sensillerin yapısı ve konumu ayrıntılı bir biçimde incelenerek bu çalışmada gösterilmiştir.

Anahtar Kelimeler: Böhm, Trichodea, Squamiformia, Chaetica, Basiconica, Auricillica, Clavate

\section{Introduction}

The antenna of insects are organs of olfaction. They are beset with different sensilla which help them in primary functions of life, that is, food and reproduction (Zacharuk, 1980; Skiri et al., 2005). These sensilla show morphological and ultrastructural differences with different functions, which act as communication channels to respond to stimuli time to time. (Gao et al., 2007). Antennal sensilla are extremely sensitive to odours thus offering a great advantage to an insect to perceive and respond to the environmental cues. (Derby and Steullet., 2001). These sensilla are highly sensitive to cater to basic needs of insects i.e., food and mate by perceiving and responding (Schneider, 1964; Onagbola et al., 2008). The occurrence of such diverse types of sensilla is complementary to their diverse habitats and behaviour. (Faucheux et al., 2006). Numerous studies have been done on the antennal sensilla of order Lepidoptera using electron microscopy techniques (Victor et al., 1999; 2003; 2008; Faucheux, 1990a; Faucheux et al., 2006; Frank et al., 2010; Nasra, 2008), but little research has involved butterflies. Therefore, the present study uses scanning electron microscopy (SEM) to 
characterize the antennal sensilla of male butterflies and providing a particular morphological basis for future behavioural and electrophysiological studies.

\section{Materials and Methods}

Twenty specimens of each of the five species of butterflies included in these investigations were collected from different places in Chandigarh, particularly Botanical Garden, Terraced Garden, Sukhna Lake etc. The names of the five species along with their respective families are mentioned in the given observations.

Identification of the given species was confirmed by referring to a book on Butterflies of North-West India (Pajni et al., 2006). The collected butterflies were transferred to a killing bottle containing a plug soaked in ethyl acetate. The freshly killed butterflies were then stretched on a stretching board and allowed to dry before shifting to insect boxes. The boxes were provided with powdered naphthalene balls to protect them from attack of insects.

Antennae of five male butterflies of each species were carefully removed from either basis. These were dehydrated by keeping them in $70 \%, 90 \%$ and $100 \%$ ethanol for 15 minutes each. The antennae were totally dried and specimens were mounted on SEM stubs equipped with double-sided adhesive tape. The specimens were then sputter-coated with gold and photographed with a Jeol JSM 6100 SEM. Different parts of each antenna were photographed according to the presence of sensilla on each of them.

\section{Results}

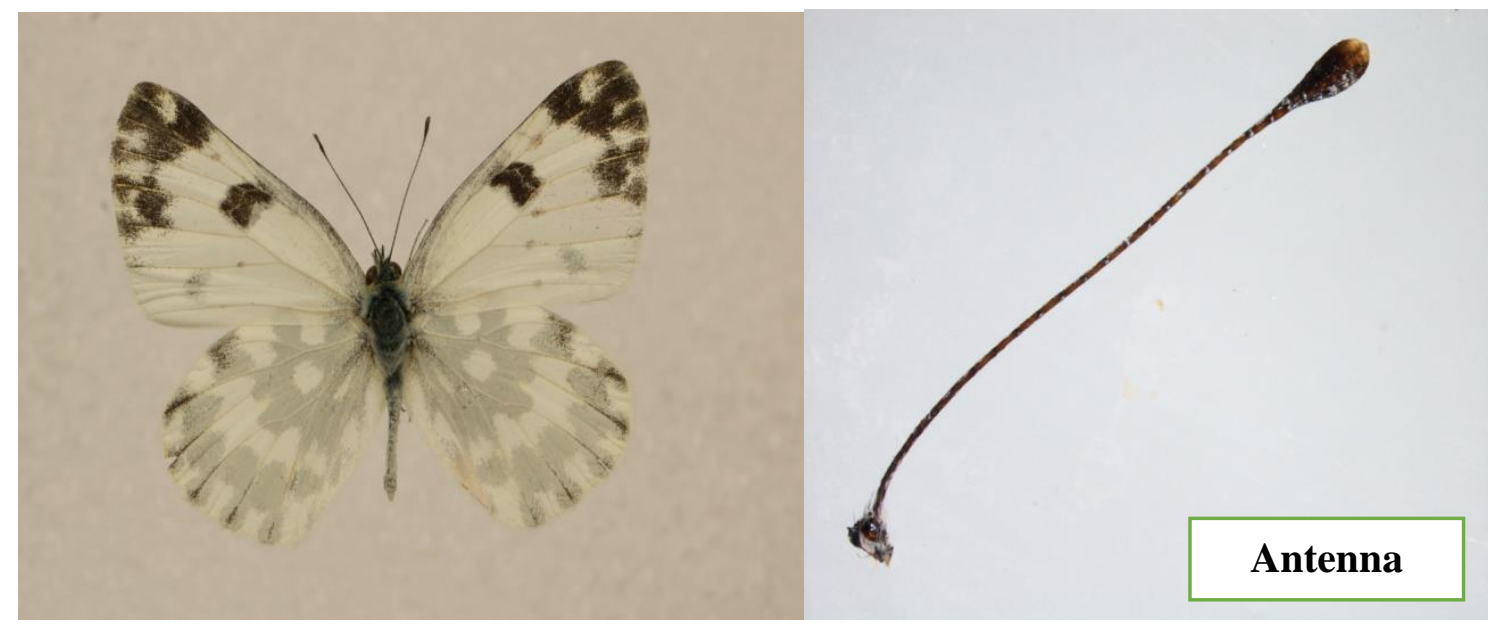

Figure 1: Pontia daplidice moorie (Rober) The Bath White

\section{Scape}

Böhm: Short and medium spine-like structures. Present in clusters. Inserted in the middle of scape. See Figure 1.1.

Trichodea: Long and medium erect structures. Less in number. Present on the dorsa 1 surface of scape. See Figure 1.1.

\section{Pedicel}

Covered with scales. See Figure 1.2.

\section{Flagellum}

Trichodea: Long, spine-like structures bearing a sharp tip and curved along longitudinal axis. Abundant. Present laterally and in the middle of flagellar segments. See Figure 1.3.

Chaetica: Straight, blunt tip, grooved surface, longer and wider at the base and arise from a round socket. Evenly distributed. Mostly present on the lateral side and the central area of flagellomere. See Figure 1.5. 
ÇOMÜ Zir. Fak. Derg. (COMU J. Agric. Fac.)

2021: 9 (1): 1-12

ISSN: 2147-8384 / e-ISSN: 2564-6826

doi: 10.33202/comuagri.876246

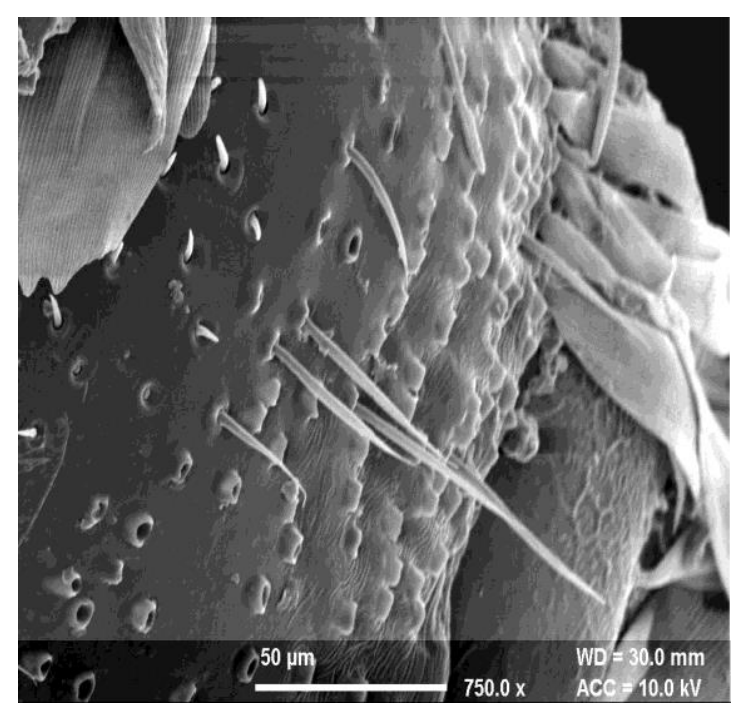

Figure 1.1 Böhm and Trichodea sensilla

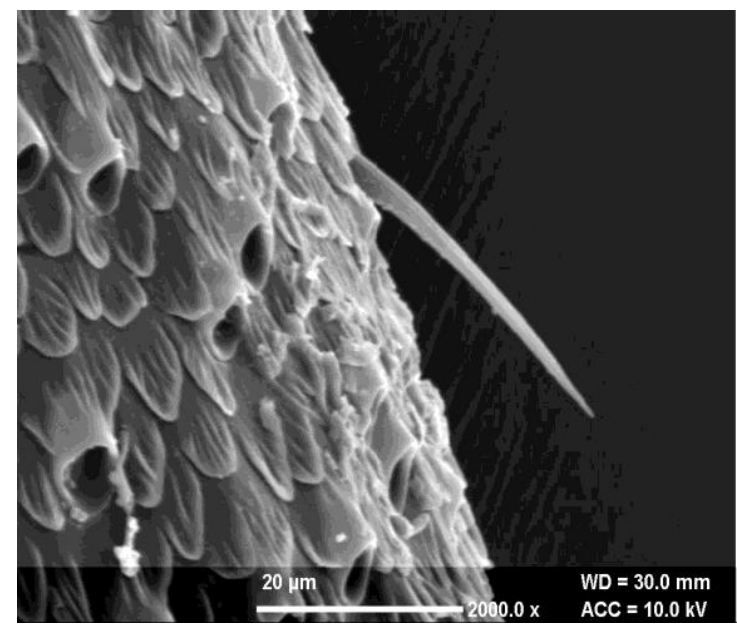

Figure 1.3 Sensillum trichodeum

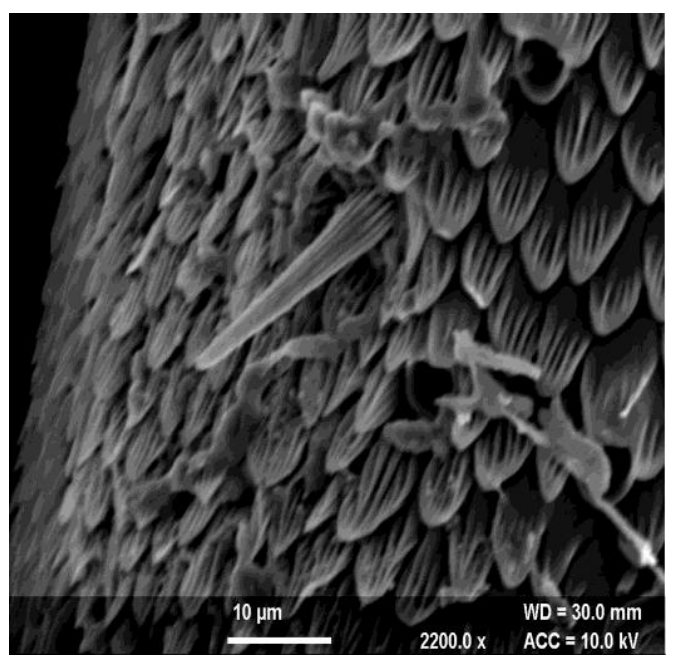

Figure 1.5: Sensillum chaeticum

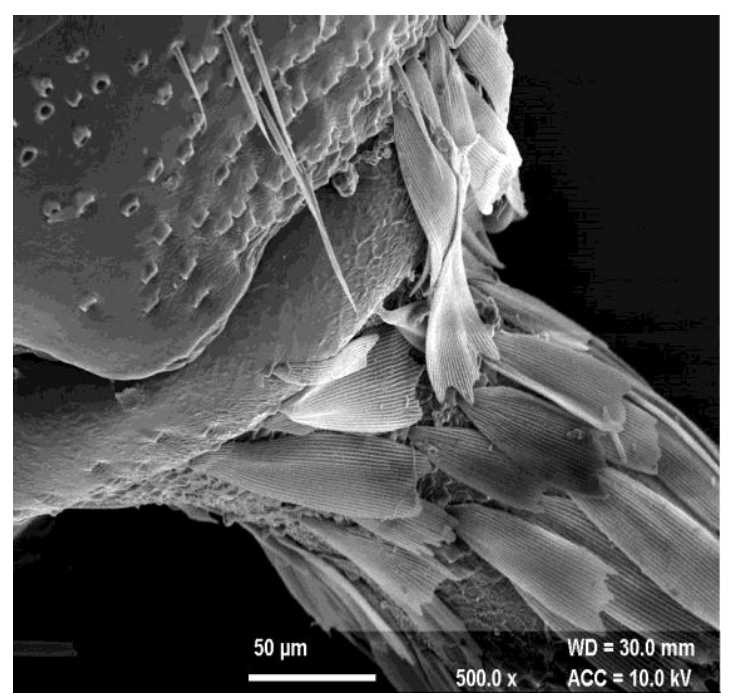

Figure 1.2: Pedicel covered with scales

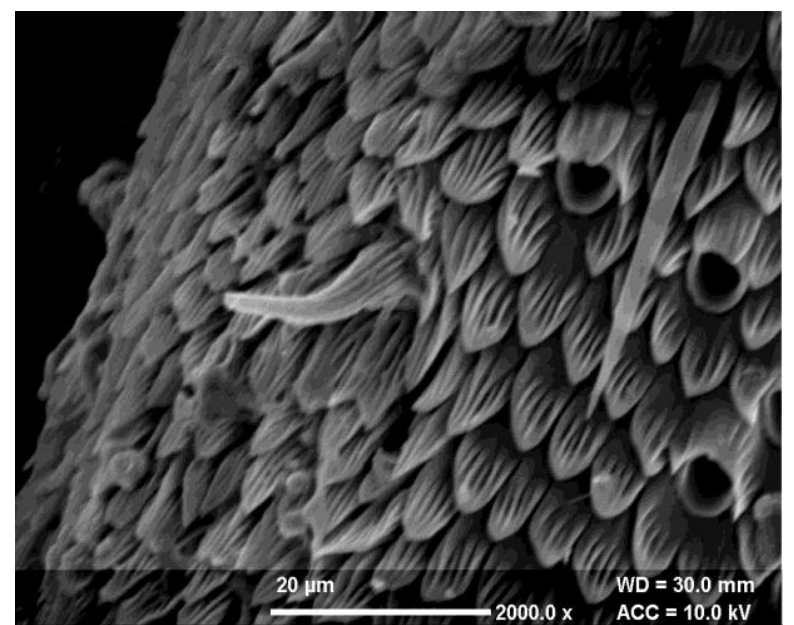

Figure 1.4 Sensillum squamiformium and basiconicum

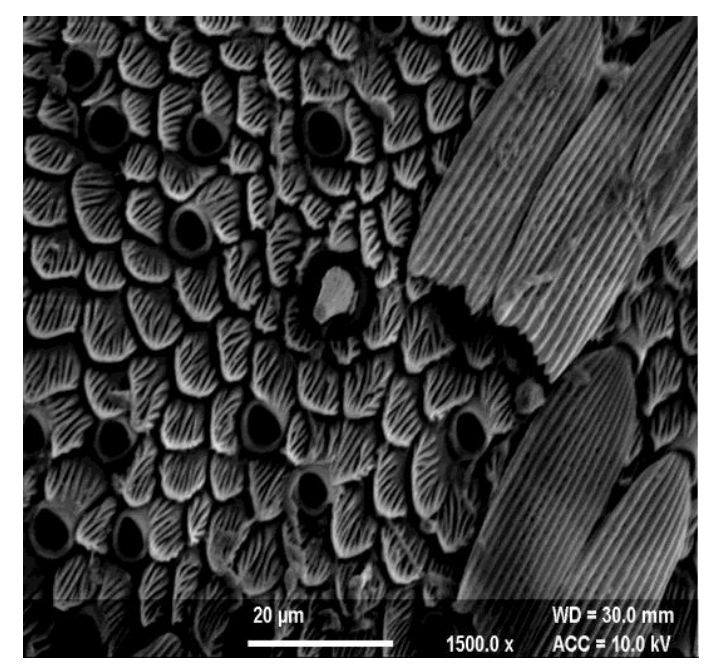

Figure 1.6: Sensillum basiconicum 
Basiconica: Curved proximally, digitiform, corrugated surface texture and wider at the base. Rarely distributed on each flagellar segment. Mostly present on the terminal segment of flagellum (Figure 1.6)

Squamiformia: Scale-like, bearing longitudinal warts and elongated with a tapering end. All antennal segments bear one sensilla except the terminal segment. Found along the base or centre of flagellum (Figure 1.4)
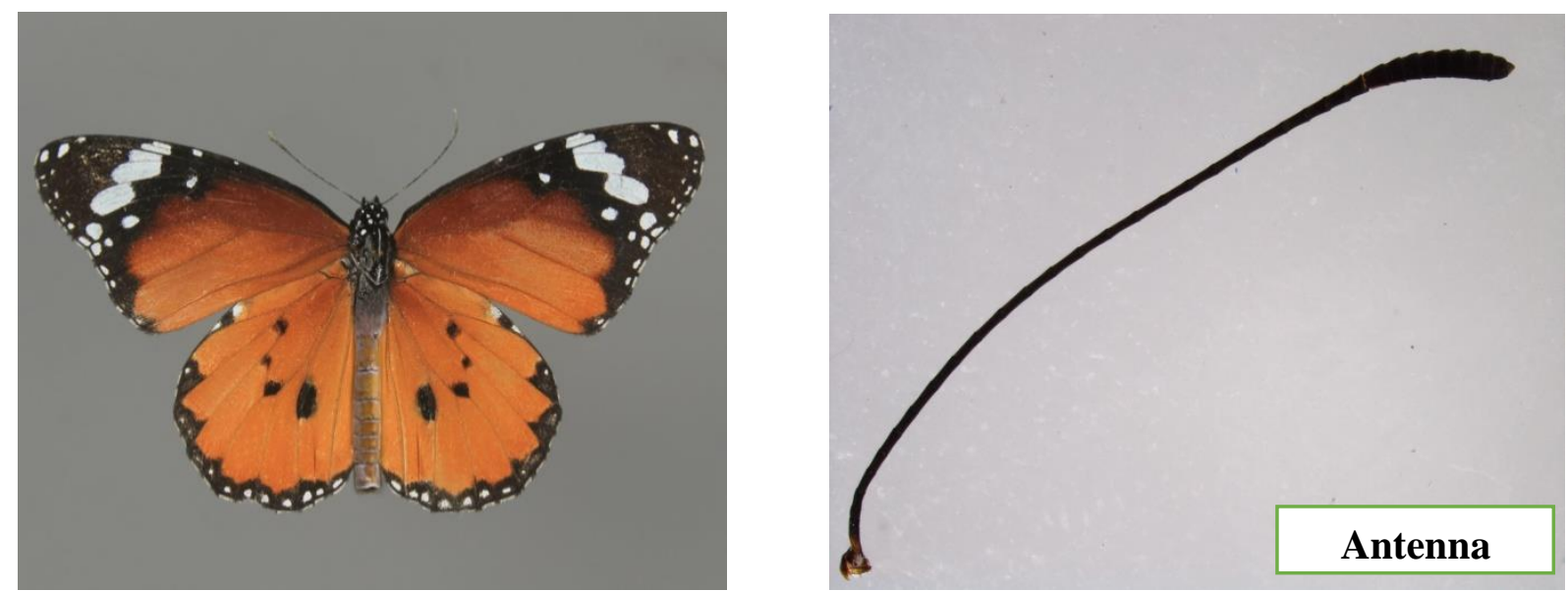

Figure 2: Danaus chrysippus (Linnaeus) The Plain Tiger

\section{Scape}

Böhm: Short (Round base and curved towards the shaft with a blunt tip) and long (Spindleshaped). Present in clusters. Inserted in the middle of scape. See Figure 2.1.

Pedicel

Trichodea: Hair-like, elongated, curved along longitudinal axis, and tapering apically. Scattered and intermingled among scales. Widely spread over the pedicel.

Böhm: Spine-like structures. Short in size. Inserted to the base of pedicel. See Figure 2.2.

\section{Flagellum}

Trichodea: Long, hair-like, curved along longitudinal axis, pointed towards the shaft and tapering apically. Less in number. Found mostly among squamiformia on the lateral edges of flagellar segment. See Figure 2.2.

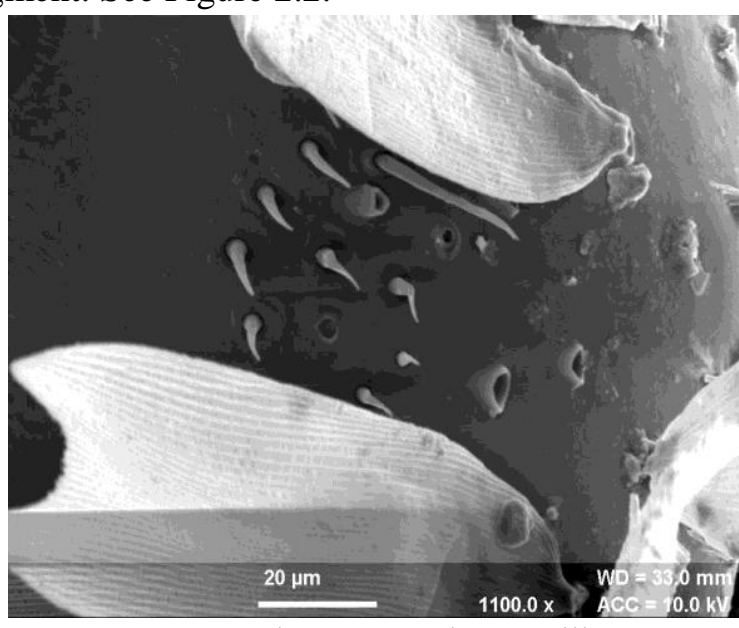

Figure 2.1 Böhm sensilla

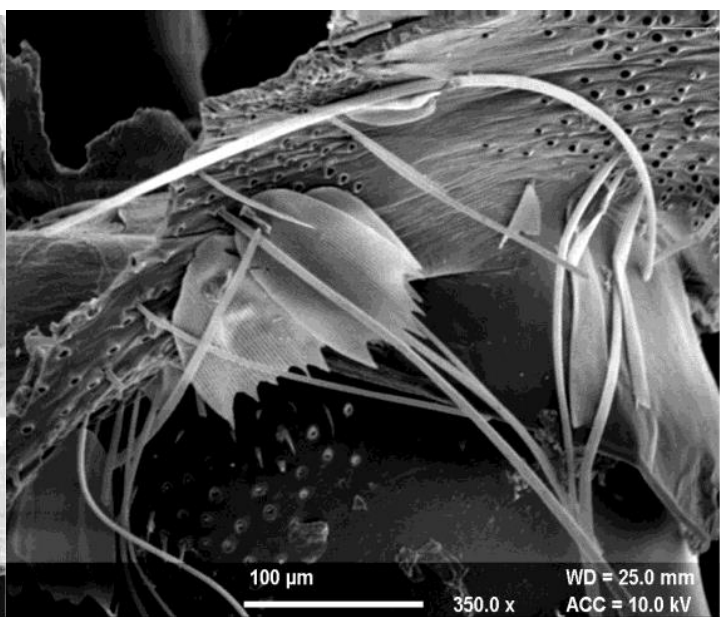

Figure 2.2 Böhm and trichodea sensilla 


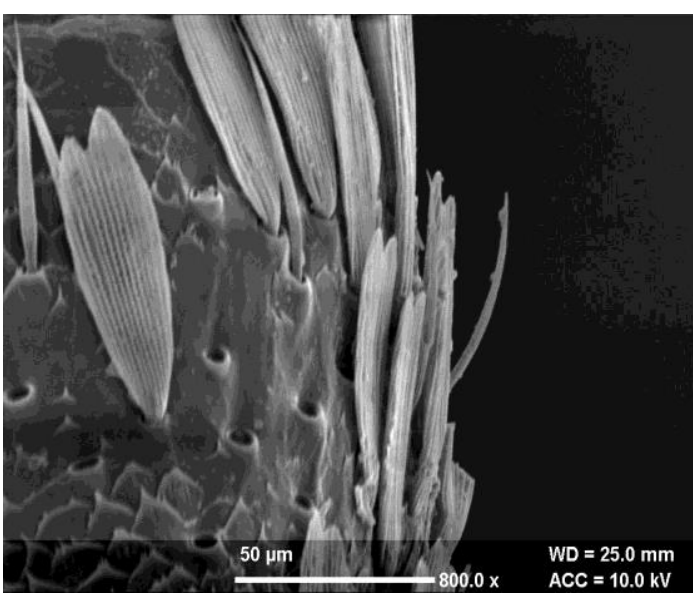

Figure 2.3 Sensilla squamiformia and trichodea

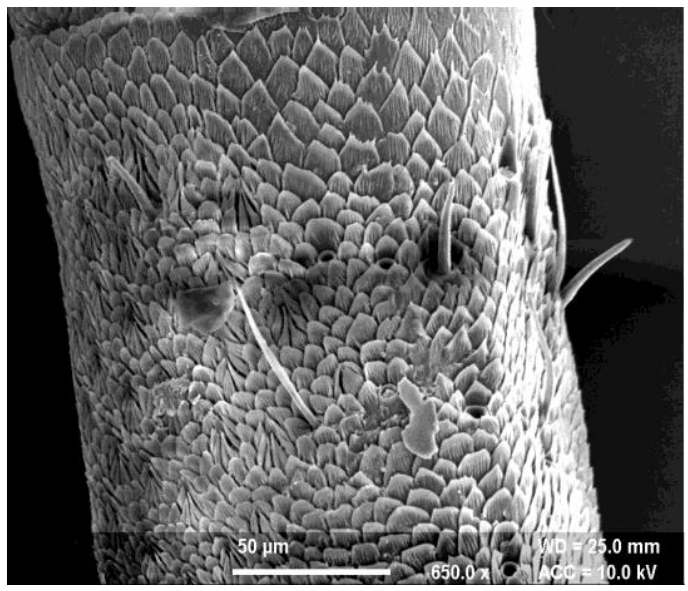

Figure 2.4 Sensilla chaetica and coeloconica

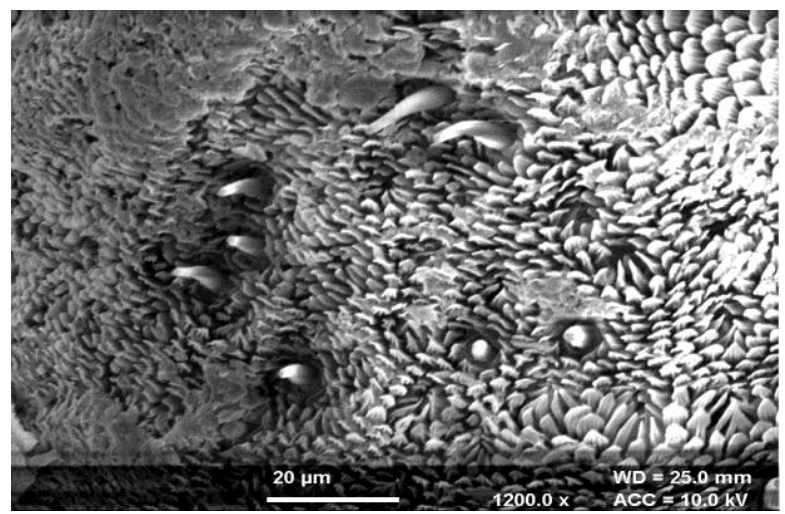

Figure 2.5 Sensilla basiconica and coeloconica

Squamiformia: Elongated, placed into socket and bear longitudinal ridges. 3-4 sensilla per flagellomere. Found over the lateral sides and in central area of the flagellar segment. See Figure 2.3.

Chaetica: Medium, slightly curved towards the tip along with corrugated surface texture. 2-3 sensilla per flagellomere. Present on the lateral edges and central area of flagellar segment. See Figure 2.4 .

Coeloconica: Peg in pit i.e. a cuticular depression surrounded by 10-12 cuticular spines forming a circle around the peg. Numerous. Spread widely over the base, centre and anterior surface (terminal segment) of the flagellomere. See Figure 2.4, 2.5.

Basiconica: Curved proximally, digitiform, round at the tip and wide at the base. 3-5 sensilla along with coeloconica distributed at the anterior surface of the terminal segment. See Figure 2.5.

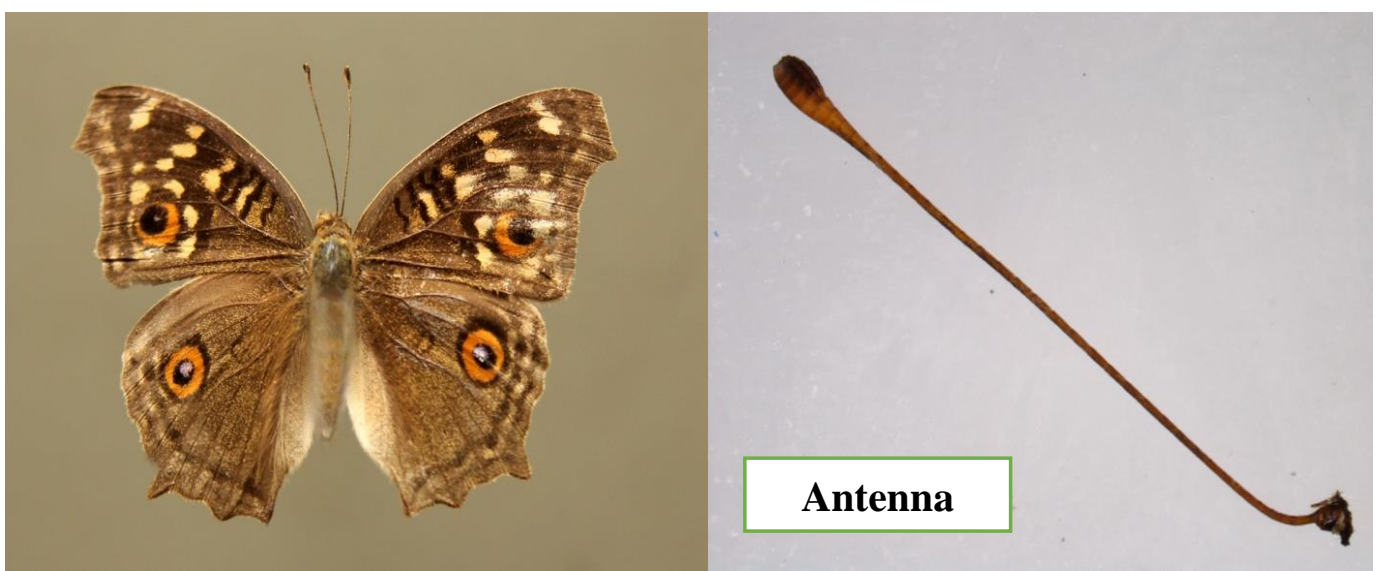

Figure 3: Junonia lemonias (Linnaeus) The Lemon Pansy 


\section{Scape}

Böhm: Short, medium and long spine-like structures curved apically. Present in groups, placed at basal portion of scape. See Figure 3.1.

Pedicel

Böhm: Long, erect, spine-like structure. Inserted at the base of pedicel. Found at the lateral edges of pedicel. See Figure 3.2.

\section{Flagellum}

Trichodea: Long, arc-like, pointed apically. Few in number. Present on the lateral edges of flagellum. See Figure 3.3.

Chaetica: Straight, curved distally with a blunt tip, grooved surface, broad base and sharp distal end. Numerous. Distributed along the lateral edges and central area of the flagellar segment. See Figure 3.4.

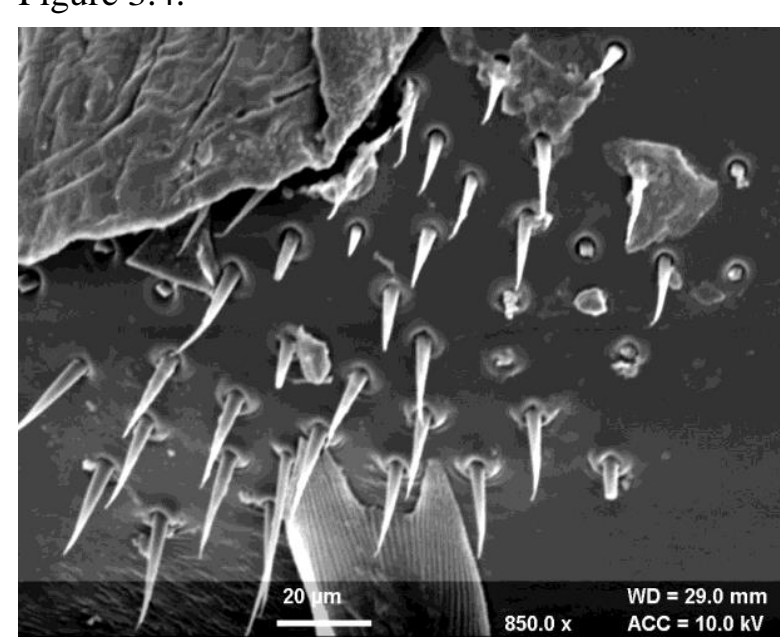

Figure 3.1 Böhm sensilla (Scape)

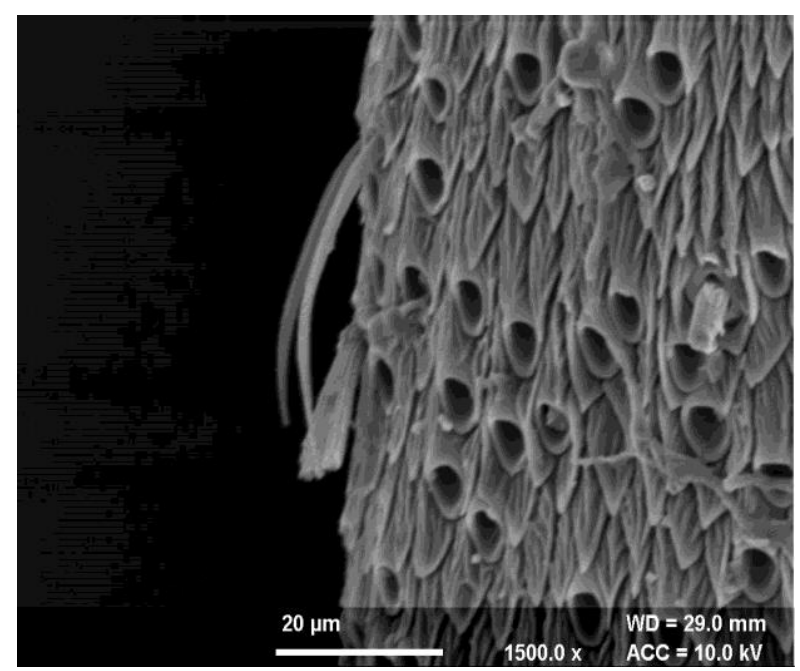

Figure 3.3 Sensilla trichodea

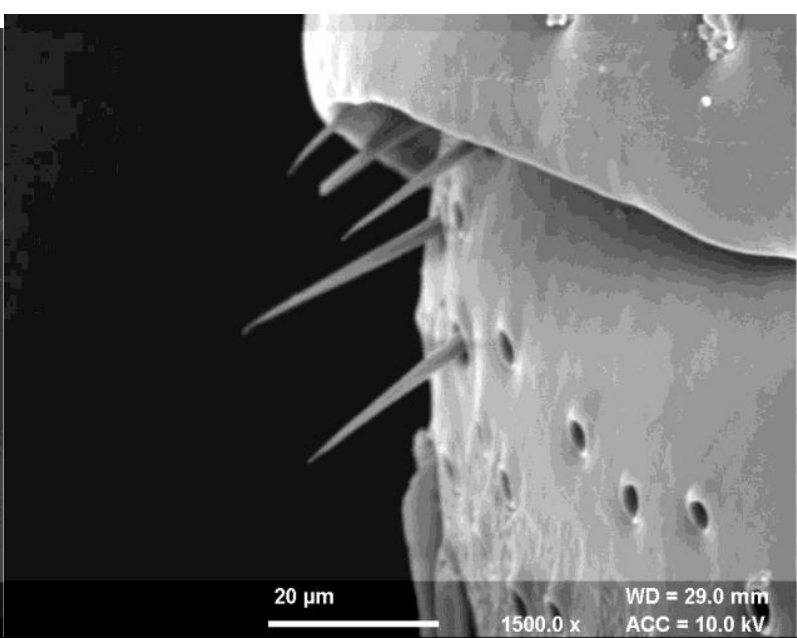

Figure 3.2 Böhm sensilla (Pedicel)

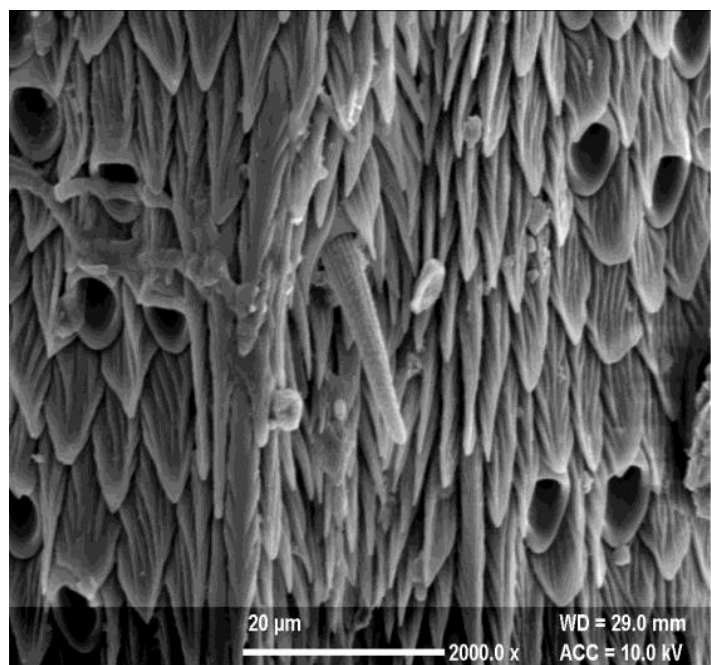

Figure 3.4 Sensilla chaeticum 


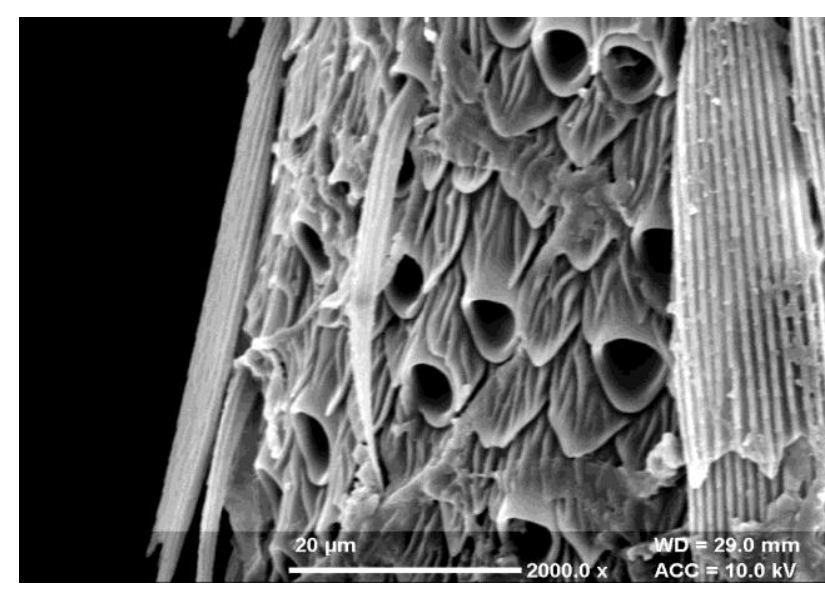

Figure 3.5 Sensillum squamiformium

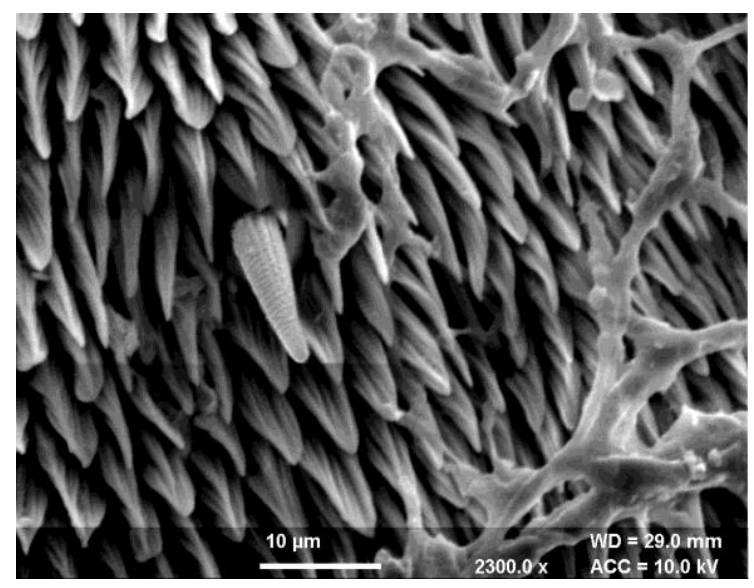

Figure 3.6 Sensillum basiconicum

Squamiformia: Scale-like, long with tapering towards end, 1-2 per flagellomere. Distributed over the lateral edges, central area and terminal segment of flagellomere. . See Figure 3.5.

Basiconica: Small, conical in shape, finger-like, corrugated surface texture and wider at the base. Less in number as compared to Chaetica. Found in the centre of the flagellar segment. See Figure 3.6.

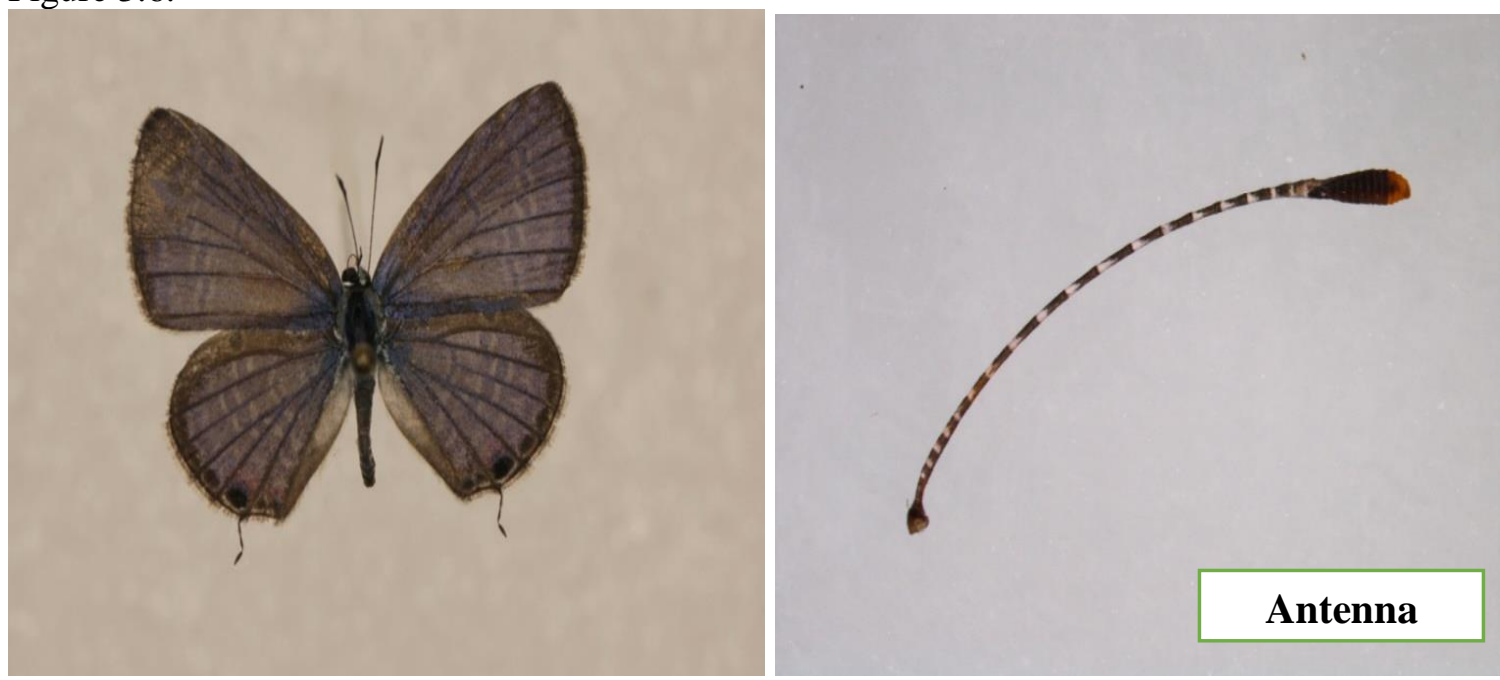

Figure 4: Chilades pandava (Horsfield) The Cycad Blue

\section{Scape}

Trichodea: Arc-like, little curved towards the antennal shaft and parallel to the antennal surface. Numerous. Present on the lateral sides of scape. See Figure 4.1.

\section{Pedicel}

Böhm: Spine-like structures. Present in groups around the base of pedicel. See Figure 4.2.

\section{Flagellum}

Trichodea: Curved along longitudinal axis bearing a blunt tip and some are hair-like, thick at base but taper towards apex. Numerous in number. Distributed on the lateral edges of the antennal surface and among the Chaetica, especially on the terminal segment. See Figure 4.4. 


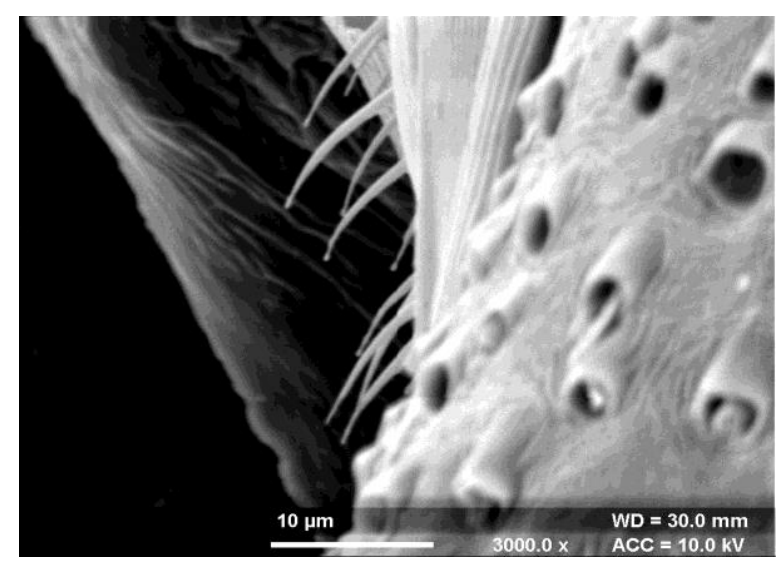

Figure 4.1 Sensilla trichodea

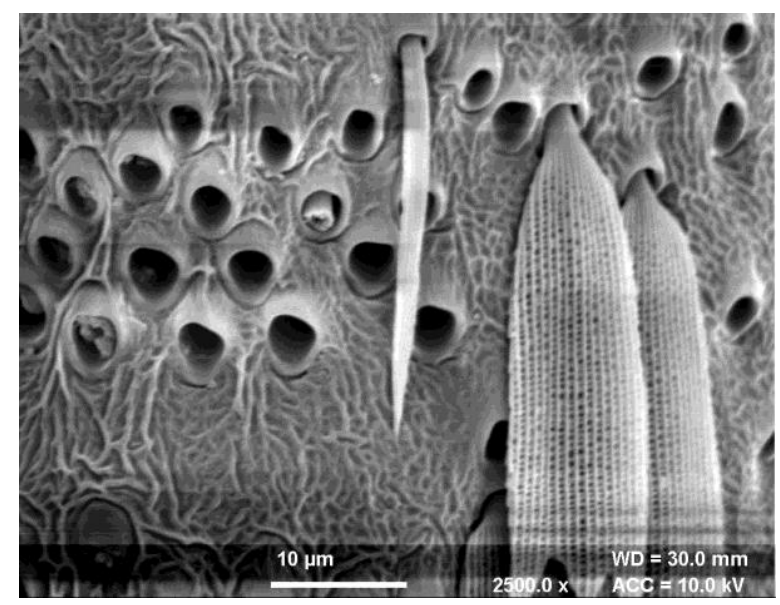

Figure 4.3 Sensillum squamiformium

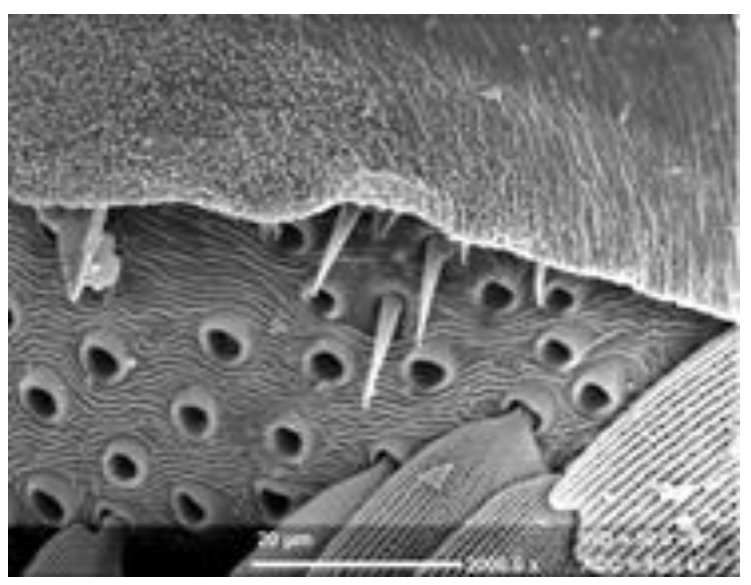

Figure 4.2 Böhm sensilla

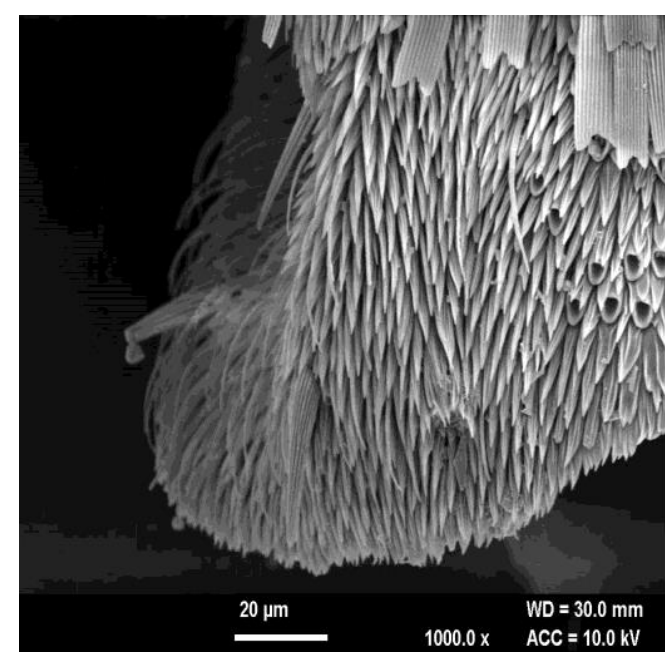

Figure 4.4 Sensilla chaetica and trichodea

Chaetica: Straight, without sharp edge and a corrugated facet, slightly curved, long and broader towards base. Evenly distributed (1-3 per flagellomere) at the centre of flagellomere and among the Trichodea along the flagellum. Present at the lateral edges of flagellar segment and spread widely among Trichodea on the terminal segment. See Figure 4.4.

Squamiformia: Scale-like, elongated, slenderer than the real scales, placed into socket and bear longitudinal warts. 1-2 per flagellomere. Found along the base and central area of flagellum among the scales. See Figure 4.3. 


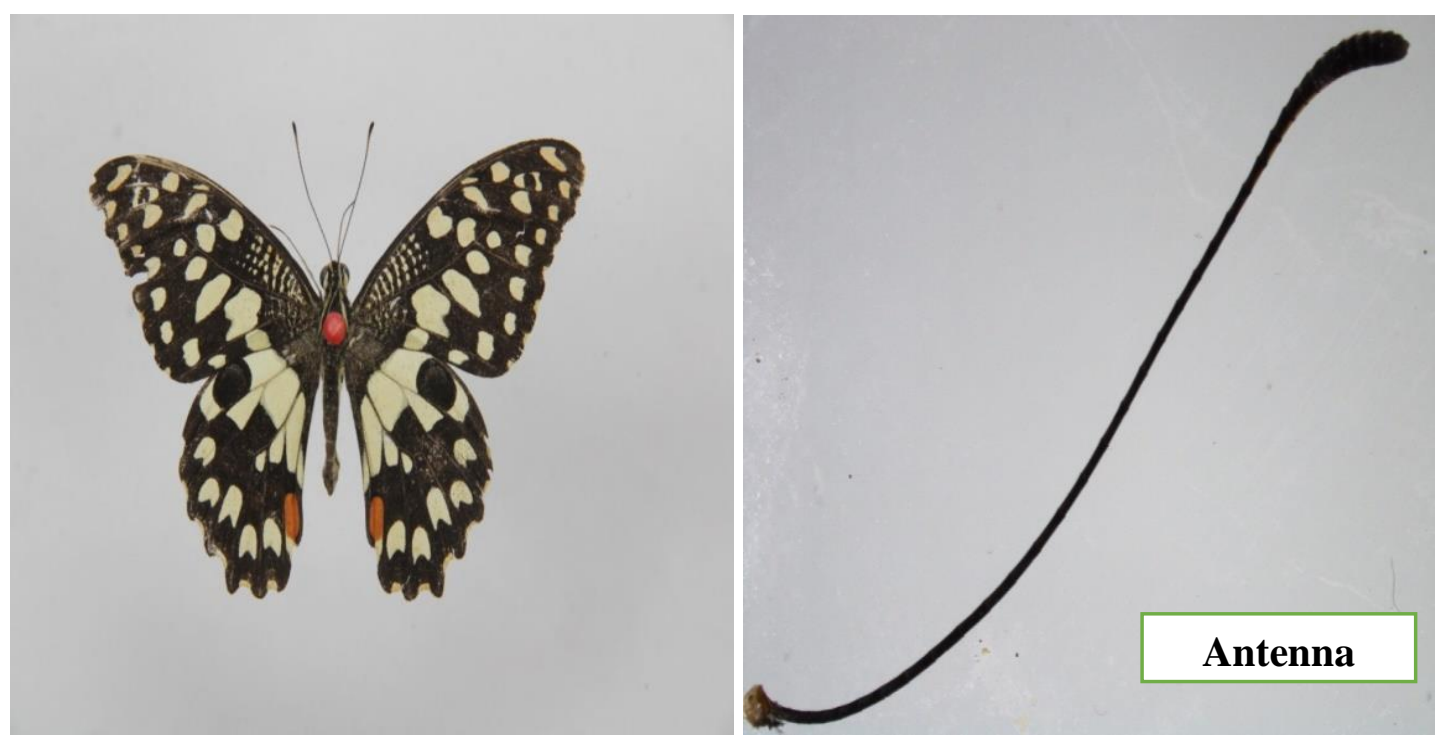

Figure 5: Papilio demoleus demoleus (Linnaeus) The Lime Butterfly

\section{Scape}

Böhm: Long and medium, needle-like, curved and pointed apically. Present in groups. Placed to the base of scape and present on its lateral edges. See Figure 5.1.

\section{Pedicel}

Covered with scales.

\section{Flagellum}

Trichodea: Arc-like with a blunt tip and parallel to the antennal surface. Abundant. Distributed in parallel bands over the flagellar segments. See Figure 5.6.

Squamiformia: Appears elongated and more cylindrical than the real scales and bears longitudinal warts. Located at the base of flagellum among the scales. See Figure 5.2.

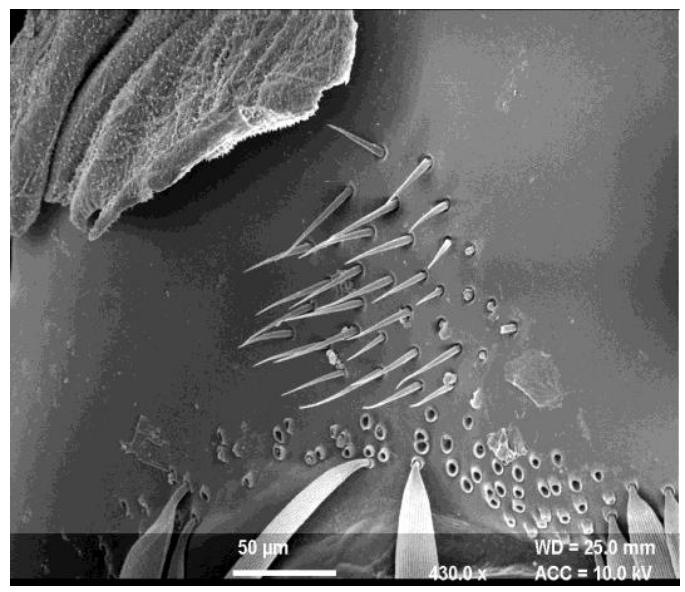

Figure 5.1 Böhm sensilla

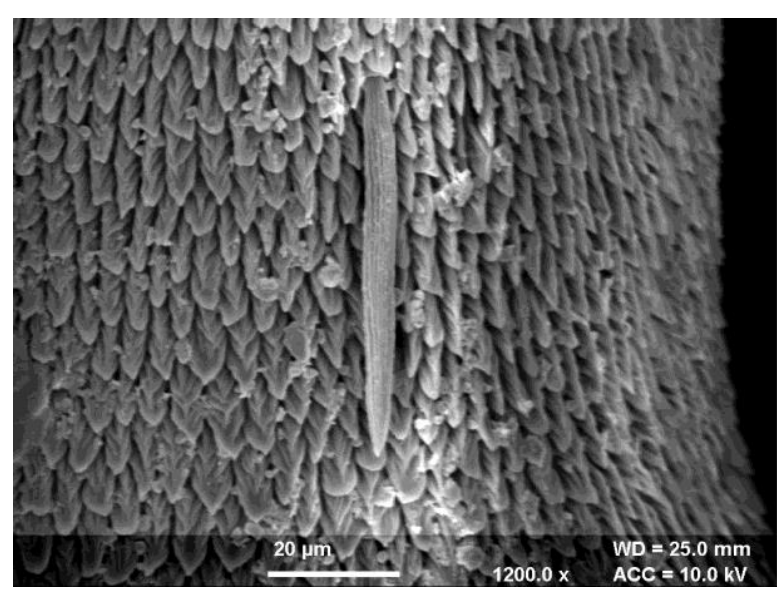

Figure 5.2 Sensillum squamiformium 


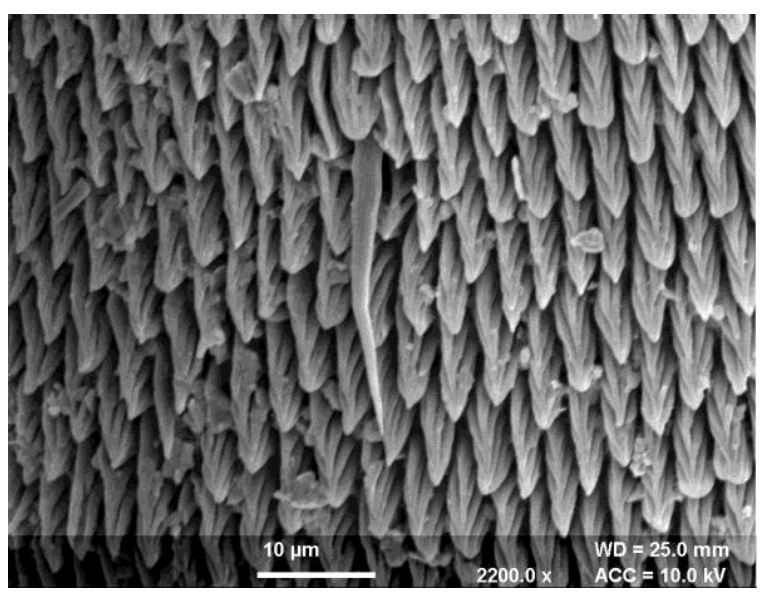

Figure 5.3 squamiformium and auricillicum

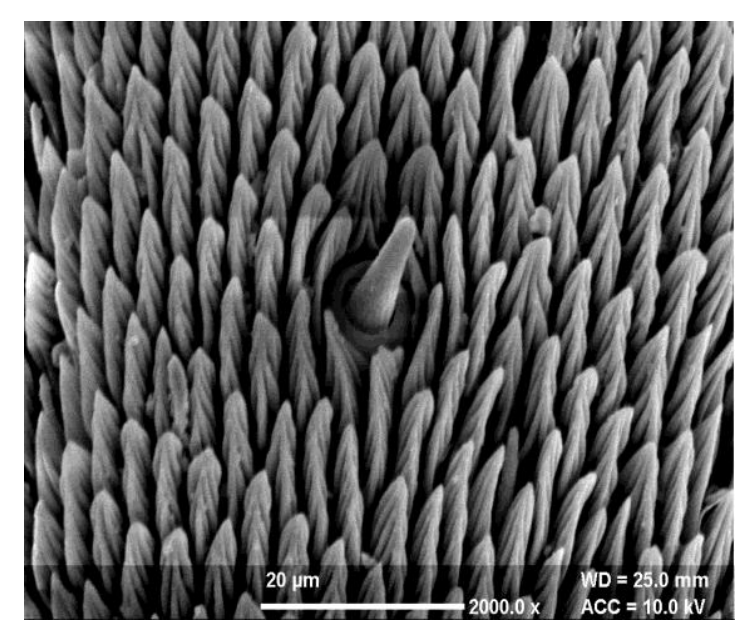

Figure 5.5 Sensillum basiconicum

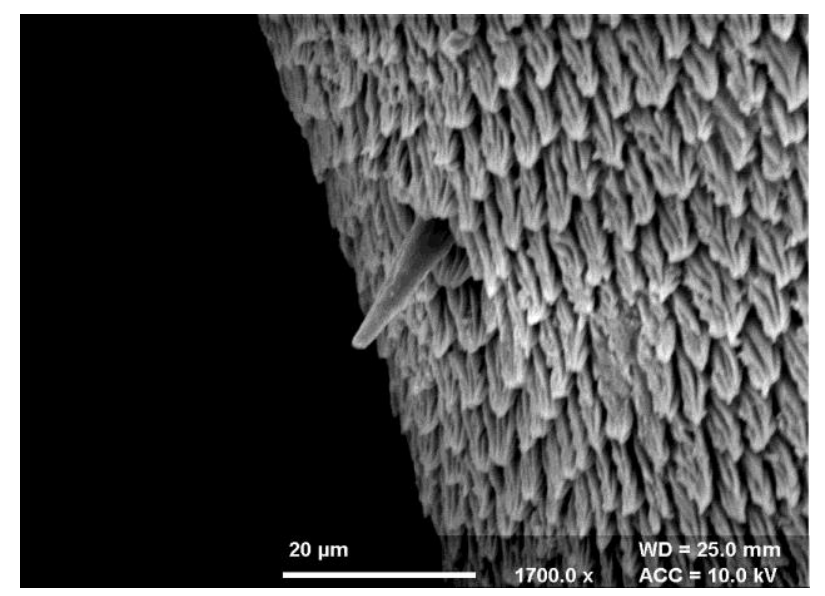

Figure 5.4 Sensillum chaeticum

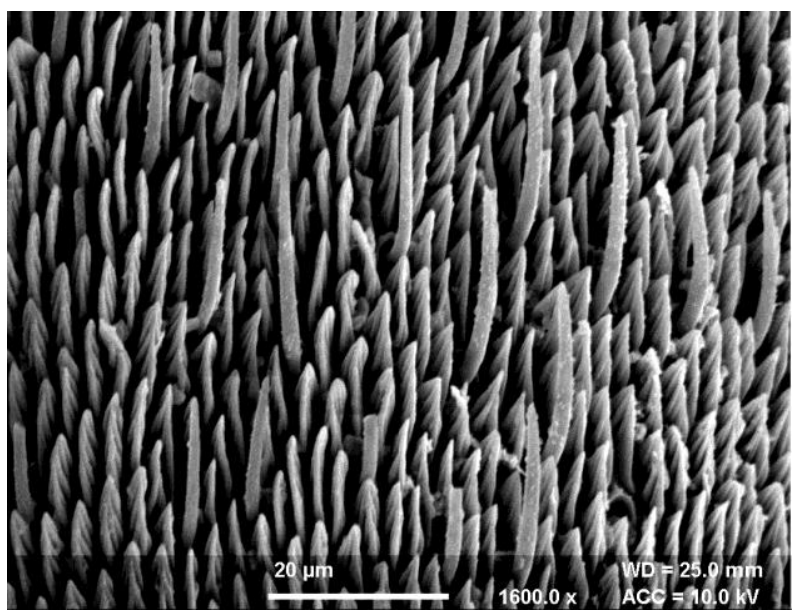

Figure 5.6 Sensilla trichodea

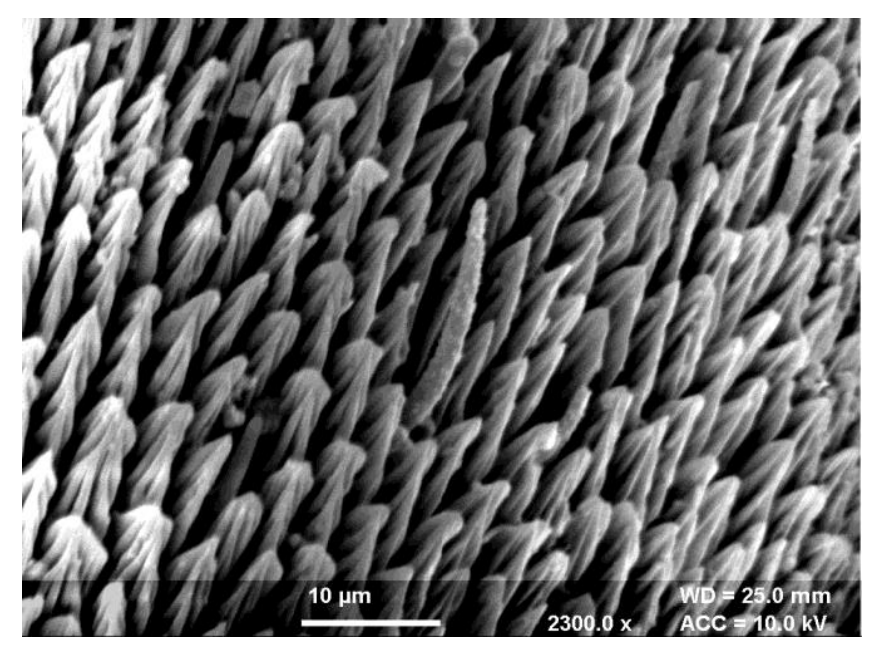

Figure 5.7 Sensilla clavate

Chaetica: Straight, medium, grooved surface, with broad base and sharp distal end. One sensillum each present per flagellomere. Found on the lateral edges and anterior surface of the terminal segment of the flagellomere. See Figure 5.4.

Clavate: Club-like. 2-3 per flagellomere. Distributed among Trichodea. See Figure 5.7. 
Basiconica: Short, blunt conical shape, corrugated surface texture and wide at the base. A single sensilla Basiconica present in 2-3 flagellar segments. Distributed in central area of flagellomere. See Figure 5.5.

Auricillica: Auriform structure, lacks sharpness at the tip, 2-3 sensilla found in a central area of a particular flagellar segment. See Figure 5.3.

In spite of the variety in the types of sensilla observed in the present investigations and studied by other workers of butterflies, it is relevant to mention the opinion of Hansson (1995) that only 3 basic type of sensilla are met with in butterflies. According to him, minor variations in the shape and size of these sensilla have led other workers to give the variants the separate names. This may be true because the number of sensilla in certain beetles (Kaur,1998), some dipterans (Wang et al., 1975) and other insects (Callahan, 1975) is also 3. However, contention of Hansson that sensilla coeloconica and auricillica are missing from butterflies has been refuted by Xiangqun et al., 2014 who reported both the sensilla in four Skipper species of butterflies and by Abu-shall and Tawfeek (2015) who observed the presence of sensilla coeloconica in Chilades pandava Horsfield.

The noted contradictions in the number of types of sensilla and their nomenclature clearly points to the fact that whole system of antennal sensilla needs to be reviewed with particular objective of working out a general structure and a common nomenclature for all the Lepidopteran antennal sensilla. This will help in reducing the number of types of sensilla as well as their role in the process of olfaction. This area of research accordingly needs to be examined in detail.

\section{Conclusions}

Detailed morphological studies regarding location and distribution of different sensilla on the antenna of five male species of butterflies pertaining to five families viz., Danaidae, Pieridae, Nymphalidae, Lycaenidae and Papilionidae from order Lepidoptera has been carried out for the first time. The electron microscopic scanning of the dealt with species by and large showed the same basic structure i.e. scape, pedicel and flagellum, each possessing different types of antennal sensilla showing morphological differences. More elaborate studies need to be undertaken on other members of the above mentioned five families which will further help in consolidating taxonomy and phylogeny of Lepidoptera.

Acknowledgements: The guidance provided by Late Dr. H.R.Pajni in shaping this manuscript is greatly acknowledged.

\section{References}

Abu-shall, A.M.H. and Tawfeek, M.E., 2015. Description of the Egyptian form of Chilades pandava Horsfield (Lepidoptera: Lycaenidae: Polyommatinae) and Ultrastructure of Antennal Sensilla. Journal of Entomology. 12: 67-76.

Callahan, P.S., 1975. Insect antennae with special reference to the mechanism of scent detection and the evolution of the sensilla. Int. J. Insect Morphol. Embryol. 4(5): 381- 430.

Derby C. D., Steullet P., 2001. Why do animals have so many receptors? The role of multiple chemosensors in animal perception. Biological Bulletin. 200: 211-215.

Faucheux M. J., 1990a. External structure of sensilla on the male and female flagellum of Noctua pronuba L. (Lepidoptera: Noctuidae). Annales de la Société Entomologique de France. 26: 173-184.

Frank D. L., Leskey T. C., Bergh J. C., 2010. Morphological characterization of antennal sensilla of the dogwood borer (Lepidoptera: Sesiidae). Annals of the Entomological Society of America. 103 (6): 993-1002.

Faucheux M. J., Kristensen N. P., Shen-Horn Y., 2006. The antennae of neopseustid moths: morphology and phylogenetic implications with special reference to the sensilla (Insecta, Lepidoptera, Neopseustidae). Zoologischer Anzeiger. 245 (2): 131-142.

Gao Y., Luo L. Z., Hammond A., 2007. Antennal morphology, structure and sensilla distribution in Microplitis pallidipes (Hymenoptera: Braconidae). Micron. 38: 684-693

Hansson, B.S., 1995. Olfaction in Lepidoptera. Experientia. 51: 1003-1027.

Kaur, D., 1998. 'A study of polymorphism in Zabrotes subfasciatus (Boh.) (Bruchidae: Coleoptera: Insecta)'.Ph.D. Thesis, Panj. Univ., Chandigarh.

Nasra, M. H., 2008. Effect of flufenoxuron on the antennal sensilla of Spodoptera littoralis (Lepidoptera: Noctuidae). Egyptian Academic Journal of biological Sciences. 1 (2): 13-25. 
Onagbola, E. O., Meyer, W. L., Boina, D. R., Stelinski, L. L., 2008. Morphological characterization of the antennal sensilla of the Asian citrus psyllid, Diaphorina citri Kuwayama (Hemiptera: Psyllidae), with reference to their probable functions. Micron. 39: 1184-1191.

Pajni, H.R., Rose, H.S., Walia, V.K., 2006. Butterflies of North-West India. Part-1.115 (Published by Atma Ram and Sons, Chandigarh).

Schneider, D., 1964. Insect antennae. Annual Review of Entomology. 9: 103-122.

Skiri, H.T., Stranden, M., Sandoz, J.C., Menzeli, R., Mustaparta, H., 2005. Associative learning of plant odorants activating the same or different receptor neurones in the moth Heliothis virescens. The Journal of Experimental Biology. 208: 787-796.

Victor, R. C., Jorge, V.C., Juan, C.T., Mario, C.L., Rodolfo, O.O., 1999. Morphology and distribution of the sense organs on the antennae of Copitarsia consueta (Lepidoptera: Noctuidae). Florida Entomologist. 82 (4): 546-555.

Victor, R. C., Guadalupe, N., Jorge V., Federico, C., Julico, C.R., 2003. The antennal sensilla of Zamagiria dixolophella Dyar (Lepidoptera: Pyralidae). Annals of the Entomological Society of America. 96 (5): 672-678.

Victor, R. C., Jorge, V.C., 2008. Morphological characteristics of antennal sensilla in Talponia batesi (Lepidoptera: Tortricidae). Annals of the Entomological Society of America. 101 (1): 181-188.

Wang, I.W.C., Axtell, R.C., Kline, D.L., 1975. Antennal and Palpal sensilla of the sand fly Culicoides furens (Poey) (Diptera: Ceratopogonidae). Int. J. Insect Morph. Embryol. 4(2): 131-149.

Xiangqun, Y., Ke, G., Feng, Y., Yalin, Z., 2014. Ultrastructure of antennal sensilla of four skipper butterflies in Parnara sp. and Pelopidas sp. (Lepidoptera: Hesperiidae). Zookeys. 399: 17-27.

Zacharuk, R.Y., 1980. Ultrastructure and function of insect chemosensilla. Annual Review of Entomology. 25: 27-47. 